\title{
MODELING AND ANALYSIS OF THE MOTIVATIONS OF FAST FASHION CONSUMERS IN RELATION TO INNOVATIVENESS
}

\author{
Canan Saricam*, Nazan Erdumlu \\ Istanbul Technical University, Faculty of Textile Technologies and Design, Istanbul, Turkey. \\ ${ }^{*}$ Corresponding author e-mail: saricamc@itu.edu.tr
}

\begin{abstract}
:
In this study, fast fashion concept is investigated in order to understand the motivations of the consumers that make them adopt these products because of their willingness for the innovativeness. The relationship between the motivational factors which were named as "Social or status image" and "Uniqueness" as expressions of individuality, "Conformity" and the willingness for "Innovativeness" is analyzed using a conceptual model. Exploratory factor analysis, confirmatory factor analysis and structural equation modeling were used to analyze and validate the model. The data used for the study was obtained from 244 people living in Turkey. The findings showed that the motivational factors "Social or status image" and "Uniqueness" as expressions of individuality are influential on the consumers' willingness for "Innovativeness".
\end{abstract}

\section{Keywords:}

fast fashion; innovativeness; consumer; individuality; conformity; uniqueness; social image; status image

\section{Introduction}

Introduced firstly by renowned global retailers Zara and H\&M, fast fashion industry grew rapidly [1] with the profit margin of $16 \%$ whereas it was $7 \%$ for traditional apparel industry $[2,3]$. Thus, it is very important for the retailers to understand the reasons lying beneath the approach of the consumers towards these products.

Constituting an emerging and important market segment of today's fashion industry, fast fashion consumers were analyzed in a limited number of studies. Bhardwaj and Fairhurst [1] described perception of fast fashion from supplier and consumer perspectives and underlined the fact that the profitability can be increased by knowing how and to what extent rapid changing fashion affects consumers' purchase behaviour and satisfaction levels. Wang [4] described and analyzed the similarities and differences between fast fashion consumer behaviour characteristics and general consumer behaviour theories by focusing on the individual differences and group influence. Watson and Yan [5] explored the differences between fast fashion and slow fashion consumers in regards to their consumer decision process stages; i.e. purchase/consumption, post-consumption evaluation, and divestment. Gabrielli, Baghi and Codelupi [6] analyzed the practices of consumption of fast fashion products by defining what fast fashion means for the consumers and how they characterize the experience of consuming it. The authors underlined the fact that fast fashion referred to the trend for individualism and added that the demands of the consumers in terms of freedom of choice and social approval should be handled together in order to understand their decision. But the studies mentioned here did not go into detail within the motivations of the consumers about the fast fashion products, which are related with the unique characteristics of the fast fashion concept.

Fast fashion integrates the consumer preferences into design process rapidly and provides trendy and fashionable products within the short time gap between production and distribution [6]. With reference to the term "Fast" in its name, the key business strategy in fast fashion concept is reducing involved processes in the buying cycle and decreasing the lead times for delivering new fashion products into stores. This situation is highly favored by the consumers that seek innovativeness. Barnes, Lea-Greenwood [7] stated that fast fashion consumers are motivated by frequent changes more quickly compared with the traditional consumers. Apart from this, fast fashion concept promises the customers imitations of high end fashion styles [2] with affordable prices and matching quality and provides a scarce value for the consumers [8]. Thanks to these characteristics, the fast fashion consumers prefer these products for special purpose of feeling of conformity such as being accepted by receiving approval from the group member [9] or the consumers are enticed with these products to feel themselves different from others by creating social or status image in order to express individuality like the other fashionable items. Specifically, fast fashion consumers satisfy their demands of feeling themselves unique by using fast fashion products; because, fast fashion brands are reported to create uniqueness with their capability in providing scarce value due to their production in low quantities [7]. Thus, it can be stated that the adoption of fast fashion products are related with the willingness of the consumers for innovativeness and the motivations of the consumers to show their conformity to the group of people and their individuality via social or status image and uniqueness. 
The purpose of this study is to investigate the fast fashion concept in order to understand the motivations of the consumers that make them adopt these products because of their willingness for the innovativeness. Specifically, it is attempted to explain the influence of the motivations of consumers which are "Social or status image" and "Uniqueness" as expressions of individuality, and "Conformity" on the consumers' willingness for "Innovativeness" in the adoption of fast fashion products. For this aim, a model that investigates the relationship between the motivational factors influencing the consumers and the innovativeness is developed and validated. The results are interpreted and compared with the previous findings of similar studies.

\section{Background Literature}

\subsection{Fashion Innovativeness}

The adoption of new products and services by the consumers is stated to be related with consumer innovativeness [10]. Rogers [11] defines innovativeness as "the degree to which an individual is relatively earlier in adopting an innovation than other members of his system". Midgley and Dowling [12] defines innovativeness as "the degree to which an individual is receptive to new ideas and makes innovation decisions independently of the communicated experience of others". Hirshman [13] defines this concept as "inherent novelty seeking" and argues that "the desire to seek out the new and different is conceptually indistinguishable from the willingness to adopt new products". Goldsmith loomed large the global characteristics of innovativeness by defining the innovativeness as the "willingness to try new things".

Innovativeness was tried to be measured by the researchers in case that the consumers are assigned to single adopter category such as (innovators, early adopters, early majority, late majority or laggards) or the relationships between innovativeness and other variables are tried to be examined [14]. For the determination of innovativeness, Rogers [11] proposed a time adoption method; Midgley and Dowling [12] proposed the use of cross sectional method which pre-specified the list of new products a particular individual has purchased at the time of the survey. On the other hand, Goldsmith and Hofacker [14] proposed a domain specific innovativenessDSI, since it was discovered that the consumers who adopt the newest products earlier than the rest may be identified to be laggards for the other type of products. DSI, developed by Goldsmith and Hofacker [14], included a six item Likert scale was used for measuring consumer innovativeness in specific product field [15].

The innovativeness concept and specifically the innovators that adopt this concept were given a special importance in terms of acceptance and adoption of the products [15] as they have significant impact on the success or failure of new products and services [16]. Innovators were reported to play a significant role in the diffusion of new products [17] because of their potential to be opinion leaders and being more knowledgeable about new products, more involved in product category and having greater media exposure. Fashion innovators particularly are defined as the consumers who are more interested in fashion and shopping and use clothing in order to express individuality [18]. According to Muzinicha et al. [16], who used DSI scale for understanding the female fashion innovativeness, the spread of new fashion clothing is facilitated by the fashion innovators and that is why the adoption can be increased and the sales and profits can be improved by understanding the innovators [16].

Moreover, there are some studies within the literature dealing with the investigation of the consumers' willingness for innovativeness and exploring its relationship with the motivations for product selection. Fromkin [19] suggested that there was a link between innovativeness and uniqueness, since individuals with high needs for uniqueness were more eager for the new products than the individuals with low needs for uniqueness [20]. Workman and Kidd [18] attempted to identify the differences between consumers groups, which were classified according to different level of willingness for innovativeness, in their need for uniqueness. Jordaan and Simpson [20] investigated the relationship between fashion opinion leadership, product involvement, need for uniqueness and consumers' fashion innovativeness. None of these studies concentrated specifically on fast fashion products however.

\subsection{Motivations Related with Product Selection}

Used as a tool for self expression and displaying self image [21] the driving motivational factors in the selection of clothing and fashionable items drew attention of many authors in the literature. Cholachatpinyo et al. [22] stated that the general two forces are socializating and differentiating forces in the process of fashion transformation and the impulse that drives the consumer to adopt fashion is the balance between these two forces. Specifying these forces in terms of human characteristics, Piamhongsant and Mandhachitara [23] stated that the selection of clothing could be made to easily reflect the conformity and individuality.

Piamhongsant and Mandhachitara [23] identified conformity as a circumstance in which the social influence is accepted by an individual because of the willingness to be included in a reference group. The usage of same products with the individuals within the close surroundings such as friends, peer and family can enable the individuals to have a sense of belonging and common symbols and to have an identity in the end [24]. Moreover, the individuals driven by the conformity motivation are influenced by what others might think about their selection and use of products since attention to social comparison information is an important antecedent for the sense of conformity [23]. Conformity was reported to be internally driven and affected by norms of society [23]. Resulting from normative influence, Lynn and Harris [25] stated that conformity enhances the similarity between people.

Nonetheless, based on the desire of the people to be a member of a group, the people are classified as idiocentric or allocentric and the individual may have allocentric or idiocentric behaviors depending on the situation [26]. According to Lee [26], the individual showing allocentric behavior considers in 
groups similarity not allowing distinction between in group and personal goals. But the individuals having idiocentric behavior chooses to differentiate themselves from the groups by giving higher priority to their personal goals [26]. It may also mean that while the allocentrics reflect need for conformity, idiocentrics reflect the need for individuality.

The individuality can be expressed by showing social or status image and unique self.

It is confirmed by Dodd et al [27] that clothing products are taken as signals about the personality and status of the individual that uses this product by presenting perfect ways to improve and communicate status. In fact, being classified in both status and conspicuous consumption, selection of clothing or fashion items was stated to be used by the consumers for showing wealth and improving social standing [28]. Because, in modern society, having means being and the achievement, satisfaction and life's meaning are attached with the possessions and acquisitions [29]. Moreover, the individuals often purchase products not for product's utilitarian purpose, but for their symbolic meanings [30]. Actually whereas dresses are perceived as a way of conforming to stereotype [23], the transference of symbolic meaning of a product to the self is thought to enhance the self image [31].

Workman and Kidd [18] emphasized the fact that the selection of the apparel goods was a form of uniqueness-seeking behavior. Consumers' need for uniqueness which can be obtained by product or brand acquisition was explained as the tendency of individuals to pursue dissimilarity from others in the marketplace [31]. Moreover, the need for uniqueness was stated to be used by the individuals in order to enhance the individual's self [31], or reflect the unique self 18]. Within this respect, the need for uniqueness can be regarded as the extension of the need for individuality but it covers more extreme situations. Actually, Fromkin and Lipshitz characterized the people with high uniqueness motivation as the ones that have the willing to manifest their uniqueness in spite of the risk of social disapproval [18]. On the other hand, derived by Snyder and Fromkin [32], theory of uniqueness states that individuals have a "need for separate identity" or a "need for uniqueness" and a moderate level of similarity relative to other individuals may cause the most acceptable state and most emotional satisfaction [18].

Thus, the selection of the clothing items are related with the motivations of the consumer to display conformity to the social group being belonged and the individuality via willingness to show social or status image and the need for uniqueness. In fact, there are some studies that investigated these motivations in clothing products. Piamhongsant and Mandhachitara [23] analyzed the underlying motivations of the career women's seeking for conformity by finding out the relationship between independent and interdependent self construal and social comparison information. Goldsmith and Clark [33] studied the analysis of factors affecting fashion opinion leadership and fashion opinion seeking by investigating the relationship of consumer need for uniqueness, attention to social comparison information, status consumption and role relaxed consumption.
Bertrandias and Goldsmith [34] investigated the influence of attention to social comparison information and consumers' need for uniqueness on opinion leadership and opinion seeking. Tian, Bearden and Hunter [31] developed and validated a scale for the need for uniqueness. Workman and Kidd [18] used the need for uniqueness scale to characterize fashion consumer groups. Nevertheless, these studies did not focus on fast fashion products although the fast fashion products address individualism, customization and independence in style for the customers who want to be identified with their personal style [35] and fast fashion brands' consumers have strong desire for uniqueness [36].

\subsection{Conceptual Model and Hypothesis}

Based on the literature reviewed, four variables were included within the conceptual model, which were entitled as "Innovativeness", "Conformity" and "Uniqueness" and "Social or status image" as expressions of individuality. "Innovativeness" was defined as the willingness to change via fast fashion products. "Conformity" was defined as a variable related with the willingness of the individual to be a member of a group and therefore related with the acceptance of similarity. "Social or status image" was defined as a variable related with individuality and specifically concentrated on the individuals' concerns with expressing the others, their social or status image via status or conscipious consumption. "Uniqueness" was defined as a variable again related with individuality but this time, it was specifically concentrated on the desire of the individual to be different from others with strong opposition to similarity.

The conceptual model is shown in Figure 1, and the hypotheses that were proposed to be validated are as below:

$\mathrm{H} 1$ : The extent to a fast fashion consumer to feel oneself unique will have a significant effect on the willingness for innovativeness.

$\mathrm{H} 2$ : The extent to a fast fashion consumer to feel oneself create a social or status image within the perspective of himself / herself and others' will have a significant effect on the willingness for innovativeness.

H3: The extent to a fast fashion consumer to feel oneself confirm the group to whom it is belonged to will have a significant effect on the willingness for innovativeness.

\section{Method}

\subsection{Data Collection and Questionnaire}

The data were obtained via an internet survey applied on a random sample from the population of fast fashion consumers in Turkey who purchases fast fashion products from fast fashion retailers such as Zara, H\&M, Mango etc.

The questionnaire designed for the survey contained two parts. In the first part, the socio-demographic characteristics 
and the purchasing habits of the respondents were examined. The second part included the questions for the variables "Innovativeness", "Conformity", "Social or status image" and "Uniqueness", which had 6, 4, 3 and 3 items respectively. 16 items were selected and modified from the studies established by Goldsmith and Clark [33], Eastman, Goldsmith and Flynn [28], Tian, Bearden and Hunter [31] and Goldsmith and Flynn [10] as seen in Table 3.

While the questions in the first part related with sociodemographic characteristics had different scales, the questions in the part dedicated to the variables of the conceptual model were designed by using five point-Likert scale which ranged from (1) disagree at all to (5) completely agree.

\subsection{Data Analysis}

The data set was analyzed by using IBM SPSS and IBM AMOS (Analysis of Moment Structure) 21 software. The items within the proposed conceptual model were analyzed using exploratory and confirmatory factor analyses, and the factors were identified. Before identifying the factors in exploratory factor analysis, the univariate normality of the data was examined considering the skewness and kurtosis values. There were no significant evidence for threats to normality because all the data had the skewness values $<3$ and kurtosis values $<10$ which were in accord with the proposal of Kline [38]. Moreover, multivariate normality was analyzed by Mardia's test. Within the Mardia's test, the multivariate kurtosis got the value of 28,613 , which is much lower than the computed value of 195 based on the formula $p(p+2)$ where $p$ equals the number of observed variables in the model [39]. Therefore, multivariate normality of the data was assumed in this study.

The scale reliability was assessed by calculating Cronbach's alpha. Sampling adequacy was tested by Kaiser-MyerOlkin (KMO) measure and Bartlett's test of sphericity. The multicollinearity was detected via the determinant of the correlation matrix. Factor loadings were checked and the factors were determined using an exploratory factor analysis followed with the confirmatory factor analysis, in which goodness of fit values were evaluated. After the confirmatory factor analysis, composite reliability test and construct validity test which are convergent and discriminant validity tests were applied.
The hypotheses were tested and the strength of the relationships was found using structural equation modeling (SEM). The statistical significance of the hypothesis was evaluated by comparing the actual value of critical ratio in AMOS to the preset critical value, which is the value of $t$ at the desired two tailed alpha or p-level [37]. For this study, the critical value was compared with the critical preset value of $t$ which is equal to $t=1.95$ at $p$ level $=0.05$.

The model fit was evaluated using the fit indexes. Different values are recommended by different researchers. The fit indexes that were used for comparison for both confirmatory factor analysis and structural equation modeling (SEM) within this research were given in Table 1.

\section{Results}

\subsection{Respondents' Profiles}

A total of 244 responses were analyzed and socio-demographic profile of the respondents was given in Table 2. 55\% of the respondents were female, while $45 \%$ of the respondents were male. Ages of the respondents were intensified between 18-23 (58\%) and 24-29 (32\%). Concerning the working position, 68 $\%$ of the respondents was students, $27 \%$ of the respondents was employee; whereas, only $2 \%$ of the respondents was housewives and $1 \%$ was retired. With regard to education level, $86 \%$ of the respondents had undergraduate degree, and $9 \%$ of the respondents had graduate degree. The income level of the respondents was analyzed in six groups. It was seen that, $43 \%$ of the respondents had the lowest level of income, since they were generally students. Only $11 \%$ of the respondents had relatively high income level.

The purchasing habits of the respondents were also analyzed in terms of purchasing frequency and purchase expense ratio. The results revealed that $36 \%$ of the respondents' purchases clothes twice a month followed by the $21 \%$ of the respondents that purchase clothes once a week, and $20 \%$ of the respondents stated that they purchase once in two months. $37 \%$ of the respondents spend $11-20 \%$ and $30 \%$ of the respondents spend $21-30 \%$ of their budget for purchasing clothing items. It was observed that only $8 \%$ of the respondents spend more than $41 \%$ of their budget for purchasing clothing items.

Table 1. Analysis of overall model goodness of fit using common fit indexes.

\begin{tabular}{|c|c|c|}
\hline Model Goodness of fit Indexes & $\begin{array}{c}\text { Values used for } \\
\text { comparison }\end{array}$ & Reference \\
\hline Chi-Square /degree of freedom & $<3$ & Hair et al [40] \\
\hline Goodness of fit index(GFI) & $\geq 0,9$ & Chau [41] \\
\hline Adjusted Goodness of fit index (AGFI) & $\geq 0.8$ & Hair et al. [40] \\
\hline Normalized fit index(NFI) & $\geq 0.9$ & Hair et al. [40] \\
\hline Comparative fit index (CFI) & $\geq 0.9$ & Hair et al. [40], Brown and Cudeck [42] \\
\hline Root mean square residual (RMR) & $\leq 0.08$ & $\leq 0.08$ \\
\hline Root mean square of approximation RMSEA & & Cudeck [42] \\
\hline
\end{tabular}


Table 2. Socio-demographic profile of the respondents.

\begin{tabular}{|c|c|c|c|}
\hline & & Freq. & $\%$ \\
\hline \multirow{2}{*}{ Gender } & Female & 133 & 54.51 \\
\hline & Male & 111 & 45.49 \\
\hline \multirow{5}{*}{ Age } & $18-23$ & 142 & 58.20 \\
\hline & $24-29$ & 77 & 31.56 \\
\hline & $30-35$ & 16 & 6.56 \\
\hline & $36-41$ & 3 & 1.23 \\
\hline & 41 and above & 6 & 2.46 \\
\hline \multirow{6}{*}{ Education } & Uneducated & 2 & 0.82 \\
\hline & Primary school & 0 & 0.00 \\
\hline & Secondary school & 0 & 0.00 \\
\hline & High school & 10 & 4.10 \\
\hline & Undergraduate & 209 & 85.66 \\
\hline & Graduate & 23 & 9.43 \\
\hline \multirow{5}{*}{$\begin{array}{l}\text { Working } \\
\text { position }\end{array}$} & $\begin{array}{l}\text { Housewife/ Non- } \\
\text { worker }\end{array}$ & 6 & 2.46 \\
\hline & Student & 166 & 68.03 \\
\hline & Employee & 66 & 27.05 \\
\hline & Senior manager & 4 & 1.64 \\
\hline & Retired & 2 & 0.82 \\
\hline \multirow{6}{*}{$\begin{array}{l}\text { Income level } \\
\text { (TL) }\end{array}$} & $500-1000$ & 104 & 42.62 \\
\hline & $1000-1500$ & 64 & 26.23 \\
\hline & $1500-2500$ & 38 & 15.57 \\
\hline & $2500-4000$ & 27 & 11.07 \\
\hline & $4000-6000$ & 6 & 2.46 \\
\hline & Above 6000 & 5 & 2.05 \\
\hline \multirow{5}{*}{$\begin{array}{l}\text { Purchase } \\
\text { frequency }\end{array}$} & Twice a week & 20 & 8.20 \\
\hline & Once a week & 50 & 20.49 \\
\hline & Twice a month & 89 & 36.48 \\
\hline & Once a month & 36 & 14.75 \\
\hline & Once in two months & 49 & 20.08 \\
\hline \multirow{6}{*}{$\begin{array}{l}\text { Purchase } \\
\text { expense } \\
\text { ratio }\end{array}$} & Below 10\% & 33 & 13.52 \\
\hline & $11-20 \%$ & 89 & 36.48 \\
\hline & $21-30 \%$ & 74 & 30.33 \\
\hline & $31-40 \%$ & 27 & 11.07 \\
\hline & $41-50 \%$ & 13 & 5.33 \\
\hline & Above $50 \%$ & 8 & 3.28 \\
\hline
\end{tabular}

Before conducting exploratory factor analysis, the data were screened to ensure their normality, and the analysis showed that there was no significant evidence for threats to normality. The Cronbach's alpha measure of reliability was found to be $(0.800)$, which is well above the conventionally acceptable value of 0.70 [43]. The Kaiser-Meyer-Olkin (KMO) measure of sampling adequacy was found to be sufficiently large to justify factor analysis (0.814) [44]. The result of Bartlett's test of sphericity was found significant. Since the determinant (0.06) was greater than 0.00001 , multicollinearity was not detected [45].

The exploratory factor analysis was applied to 16 items using the principal axis factoring with varimax rotation. Two items from the variable "Innovativeness" having factor loadings below 0.5 were dropped, and the rest 14 items with the factor loadings shown in Table 3 yielded four factors explaining $65.4 \%$ of the total variance. The factors obtained were labeled as "Innovativeness" (factor 1), "Conformity" (factor 2), "Social or status image" (factor 3) and "Uniqueness" (factor 4).

Factor loadings were also checked with confirmatory factor analysis to modify and to improve the model and C4 item with low factor loading $(<0.5)$ was eliminated from the variable "Conformity". The goodness of fit values in confirmatory factor analysis were observed to be within the recommended values.

In order to check reliability and validity, Composite Reliability (CR), and Average Variance Extracted (AVE) were calculated for all of the variables within the model. Showing the degree to which a concept is represented by its indicators, composite reliability of the variables were found to be higher than 0.6 [46] getting the values 0.852 for "Innovativeness", 0.705 for "Conformity", 0.836 for "Social status or image" and finally 0.717 for "Uniqueness". For assessing the convergent validity, Average Variance Extracted values for the variables were also checked and it was seen that they were approximate to or exceeded 0.5 which is an acceptable magnitude $[47,48]$ Measuring the extent to which variables differ, discriminant validity was assessed by comparing the square roots of $\mathrm{AVE}$ values and with the correlations between the variable and all other variables [49]. As the square roots of AVE values were found to be higher than the correlations between the variable and the other variables, it was confirmed that the discriminant validity was satisfied as seen in Table 4.

\subsection{Structural Equation Modeling Results}

The proposed conceptual model consisting of 4 factors with 13 items as shown in Figure 1 was tested by using structural equation modeling.

The results of the test revealed reasonable fit between the data and proposed model. The chi-square was calculated to be $116.896(p=0.000)$ with 58 degrees of freedom. The indexes calculated to judge the model fit were found to be within the recommended ranges for model acceptance (GFI $=0.931$, $\mathrm{AGFI}=0.891, \mathrm{CFI}=0.946, \mathrm{NFI}=0.900$ and $\mathrm{RMR}=0.073)$. In 
Table 3. Exploratory factor analysis results.

\begin{tabular}{|c|c|c|c|c|c|c|}
\hline \multirow{2}{*}{ Items } & \multirow{2}{*}{ Variable } & \multirow{2}{*}{ Definition } & \multicolumn{4}{|c|}{ Factors } \\
\hline & & & 1 & 2 & 3 & 4 \\
\hline 11 & Innovativeness & $\begin{array}{l}\text { I know the names of new fashion designers before other } \\
\text { people do. }\end{array}$ & 0.813 & & & \\
\hline 12 & Innovativeness & I will buy a new fashion item, even if I have not heard of it yet. & 0.811 & & & \\
\hline 13 & Innovativeness & $\begin{array}{l}\text { In general I am among the last in my circle of friends to buy a } \\
\text { new fashion item when it appears. }\end{array}$ & 0.810 & & & \\
\hline 14 & Innovativeness & $\begin{array}{l}\text { If I heard that a new fashion style was available in the store, I } \\
\text { would be interested enough to buy it. }\end{array}$ & 0.760 & & & \\
\hline C1 & Conformity & I tend to pay attention to what others are wearing. & & 0.792 & & \\
\hline $\mathrm{C} 2$ & Conformity & $\begin{array}{c}\text { My behaviour often depends on how I feel others wish me to } \\
\text { behave. }\end{array}$ & & 0.753 & & \\
\hline C3 & Conformity & It is important to me to fit into the group I am with. & & 0.684 & & \\
\hline $\mathrm{C} 4$ & Conformity & $\begin{array}{c}\text { My behaviour often depends on how I feel others wish me to } \\
\text { behave. }\end{array}$ & & 0.668 & & \\
\hline S1 & $\begin{array}{l}\text { Social or } \\
\text { status image }\end{array}$ & A product is more valuable to me if it has some snob appeal. & & & 0.855 & \\
\hline S2 & $\begin{array}{l}\text { Social or } \\
\text { status image }\end{array}$ & I would buy a product just because it has status. & & & 0.837 & \\
\hline S3 & $\begin{array}{l}\text { Social or } \\
\text { status image }\end{array}$ & I am interested in new products with status. & & & 0.519 & \\
\hline U1 & Uniqueness & $\begin{array}{l}\text { I actively seek to develop my personal uniqueness by buying } \\
\text { special products or brands. }\end{array}$ & & & & 0.852 \\
\hline U2 & Uniqueness & $\begin{array}{l}\text { I often dress unconventionally even when it is likely to offend } \\
\text { others. }\end{array}$ & & & & 0.808 \\
\hline U3 & Uniqueness & I look for one-of-a kind product to create my own style. & & & & 0.602 \\
\hline
\end{tabular}

Table 4. The correlations between the variables and the square roots of AVE values.

\begin{tabular}{|l|c|c|c|c|}
\hline & Uniqueness & $\begin{array}{c}\text { Social status or } \\
\text { image }\end{array}$ & Conformity & Innovativeness \\
\hline Uniqueness & 0.683 & & & \\
\hline Social status or image & 0.556 & 0.794 & & \\
\hline Conformity & 0.073 & 0.156 & 0.675 & 0.136 \\
\hline Innovativeness & 0.458 & 0.578 & 0.770 \\
\hline
\end{tabular}

addition, RMSEA was 0.065 and CMIN/DF was found to be 2.015 which indicated an acceptable fit.

In order to determine the validity of the hypothesis, the estimates were generated for each path and $R^{2}$ value was calculated. As $R^{2}$ got the value 0.363 , which is higher than 0.10 , for the dependent variable "Innovativeness" was found to be appropriate and informative to examine the significance of the paths associated with the factors.

The relationships with "p" values below 0.05 were found to be statistically significant. Since the "p" values for the hypothesis $\mathrm{H} 1$ and $\mathrm{H} 2$ were below 0.05 , these two hypotheses were accepted, whereas the hypothesis $\mathrm{H} 3$ was rejected. The relationships between the variables "Social or status image", "Uniqueness" and "Innovativeness" were found to be statistically significant with standardized regression weights of 0.46 and 0.20 respectively. Thus, the willingness of consumers for innovativeness is influenced by the motivations of the consumers regarding the individuality as both the variables "Social or status image" and "Uniqueness" were related with the expression of individuality.

Within these two variables related with individuality "Social status or image" was observed to have a stronger relationship 


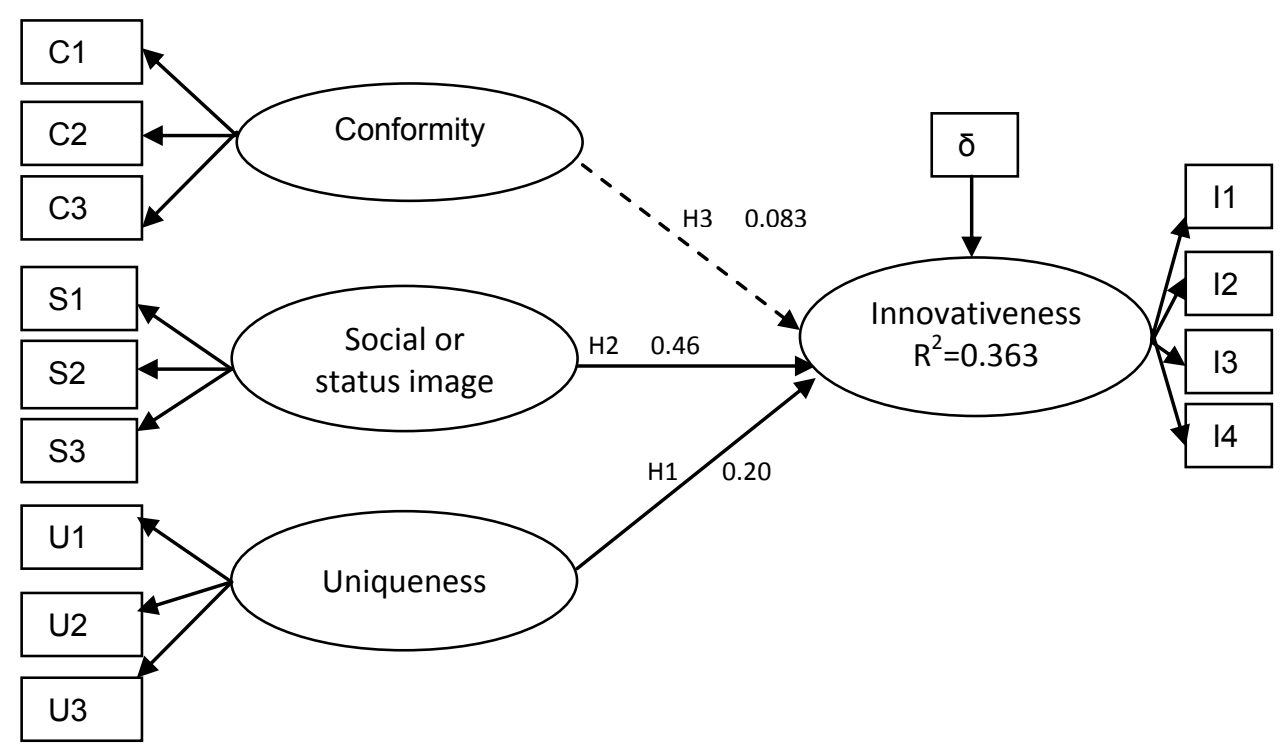

Figure 1. Proposed conceptual model.

with the variable "Innovativeness" which meant that the more the individuals are eager to express their individuality via their possessions, wealth and acquisitions, the faster they are adapting to the changes within styles, silhouettes, trends and fashion. Similarly, the higher the individuals oppose to the similarity with others, the more the willingness they feel about preferring and trying the innovative products.

Since the relationship between the variables "Conformity" and "Innovativeness" was found to be statistically insignificant, it may be revealed that group influence cannot be considered as one of the main determinants of acceptance of new products and changes in fashion.

\section{Discussion}

The findings and the regression weights of the motivational variables were generalized for the fast fashion users that live in Turkey. Thus, there is a possibility that the significance of the factors in terms of strength may change for the users that live in different countries.

Fast fashion consumers in Turkey were observed to be young and low-income people. This result is in parallel with the statement Generation $Y$ would prefer a higher number of lowquality, cheap and fashionable clothes [50], which are actually fast fashion products. Specifically, it can be stated that fast fashion products are preferred by fashion conscious but low income people that are not able to afford high quality fashionable products. Thus, fashionability and inexpensive price levels are the points of attractiveness for fast fashion consumers in Turkey. However, it is not possible to generalize this perception about fast fashion consumption in all segments of consumers and all over the world. In fact, according to Bhardwaj and Fairhurst [1] who stated that that throwaway fashion and fast fashion terms could be used interchangeably, the perception of the term varies among different generations. Moreover, it is not possible to make comparisons and further generalization about the perception of consumer and characteristics of fast fashion consumers since, the number of the studies about fast fashion in consumers' perspective is quite limited and little is reported in the literature concerning the consumer segmentation regarding the acceptance of fast fashion.

The results of the model proposed showed that most influential motivation lying beneath the willingness of the consumers for innovativeness via fast fashion products is creating "Social or status image". This finding was actually expected since the selection of fashion clothing is known to be largely influenced by the symbolic values rather than utilitarian values [23]. In fact, within the research established by Watson and Yan [5] unique style characteristics of fast fashion were reported to have congruence with the self image. Moreover, the authors [5], stated that fast fashion consumers make purchasing as they enjoy buying trendy clothing for little money and Bagwell and Bernheim [51] found out that the consumers having willingness to seem wealthy, buy a large quantity of goods at a lower price.

The secondary influential motivation was found to be "Uniqueness". This result complies with the findings of the conceptual study established by Joy et al. [2]. Joy et al [2] put forward that the fast fashion consumers that do not want to seem similar to other people, prefer the scarce or limited edition products since they wanted to look unique. Specifically, Jordaan and Simpson [20], who investigated the relationship between fashion opinion leadership, product involvement, need for uniqueness and consumers' fashion innovativeness, stated that $25.8 \%$ of fashion innovativeness can be explained by the variation in need for fashion uniqueness.

The findings mentioned above comply with the findings of Goldsmith and Clark [33] who investigated the behaviors of opinion leaders and opinion seekers. The authors found out that the opinion leaders, who can also be described as innovators and important consumers in the diffusion of new products were influenced with the status consumption and need for uniqueness. 
On the other hand, the results of the study differed from the findings of Goldsmith and Clark [33] in terms of the variable "Conformity". The authors found that there is significant relationship between attention to social comparison information where the attention to social comparison information covers the items related with the conformity and the behaviors of both opinion leaders and opinion seekers with a lower regression weight for opinion leaders. Moreover, Kim [9] found out that the importance given to apparel is related with the values regarding the sense of belonging and security to better establish relationship with others. This difference in findings in terms of the variable "Conformity" may be attributed to the fact that the respondents of the survey were selected from fast fashion consumers instead of traditional apparel consumers who may express higher sensitivity in terms of having counter-conformity motivation. Although, fashion is defined as "a form of collective behavior, or a wave of social conformity" [30] and fashion consumers follow the fashion trends in order to conform with the other people, the individuals that prefer fast fashion products may be assumed to have willingness for innovativeness. In fact, it was stated that the innovators are likely to dispose the clothing because of conformity reasons [16].

\section{Conclusions}

This study validated the model which was built to find out the relationship between the willingness for innovativeness via fast fashion products and the motivations of the consumers which were defined as, "Uniqueness" and "Social or status image" as expressions of individuality, and "Conformity".

The findings are eligible to be used by the managers in fast fashion industry in order to motivate the consumers to make the consumers purchase more fast fashion products. Based on the results, it may be suggested to the fast fashion retailers to focus more on the characteristics of the fast fashion products to present more individuality either by providing the "Social image or status" or "Uniqueness".

The model that was validated can be used by the other researchers in order to find the motivations lying beneath the adoption of the fast fashion products in different parts of the world.

Nonetheless, it is possible to extend the model to include the satisfaction level or analyzing the differences in the influential motivations for the consumers that fall into different groups in terms of innovativeness. Besides, the model can be expanded with extra analysis for seeing the influence of the factors such as age, gender and income with an additional purpose of identifying the characteristics of the fast fashion consumers and the influence of these characteristics on the motivations.

\section{References}

[1] Bhardwaj, V., \& Fairhurst, A. (2010). Fast fashion: response to changes in the fashion industry, The International Review of Retail, Distribution and Consumer Research, 20 (1), 165-173.
[2] Joy,A., Sherry, J.F., Venkatesh, A., Wang, J., \& Chan, R. (2012). Fast Fashion, Sustainability, and the Ethical Appeal of Luxury Brands, Fashion Theory: The Journal of Dress, Body \& Culture, 16 (3), 273-296.

[3] Mihm, B. (2010). Fast Fashion in a Flat World: Global Sourcing Strategies. International Business and Economics Research Journal, 9 (6), 55-63.

[4] Wang, T.Y. (2010). Consumer behaviour characteristics in fast fashion, MSc Thesis, Boras, Sweden.

[5] Watson, M.Z., \& Yan, R.N. (2013). An exploratory study of the decision processes of fast versus slow fashion consumers, Journal of Fashion Marketing and Management, 17 (2), 141-159.

[6] Gabrielli, V., Baghi, I., \& Codeluppi, V. (2013). Consumption practices of fast fashion products: a consumer-based approach, Journal of Fashion Marketing and Management, 17 (2), 206-224.

[7] Barnes, L., \& Lea-Greenwood, G. (2006). Fast fashioning the supply chain: shaping the research agenda, Journal of Fashion Marketing and Management, 10 (3), 259-271.

[8] Hayes, S.G., \& Jones, N. (2006). Fast fashion: A financial snapshot, Journal of Fashion Marketing and Management 10 (3), 282-300.

[9] Kim, H.S. (2005). Consumer profiles of apparel product involvement and values, Journal of Fashion Marketing and Management: An International Journal, 9 (2), 207 - 220.

[10] Goldsmith, R.E., \& Flynn, L.R. (1992). Identifying innovators in consumer product markets. European Journal of Marketing, 26 (12), 42-55.

[11] Rogers, E.M., \& Shoemaker, F.F. (1971). Communication of Innovations. New York: The Free Press.

[12] Midgley, D. F., \& Dowling, G.R. (1978). Innovativeness: The Concept and Its Measurement, Journal of Consumer Research, 4, 229-242.

[13] Hirschman, E.C. (1980). Innovativeness, Novelty Seeking and Consumer Creativity, Journal of Consumer Research,7(3), 283-295.

[14] Goldsmith, R.E., \& Hofacker, C.F. (1991). Measuring Consumer Innovativeness, Journal of the Academy of Marketing Science, 19(3), 209-221.

[15] Goldsmith, R.E., D'hauteville, F., \& Flynn, L.R. (1998). Theory and measurement of consumer innovativeness: $A$ transnational evaluation. European Journal of Marketing, 32(3/4), 340-353.

[16] Muzinich, N., Pecotich, A., \& Petrevu, S. (2003). A model of the antecedents and consequents of female fashion innovativeness, Journal of Retailing and Consumer Services, 10 (5), 297-310.

[17] Goldsmith, R.E., \& Newell, S.J. (1997). Innovativeness and price sensitivity: managerial, theoretical and methodological issues, Journal of Product \& Brand Management, 6 (3), 163-174.

[18] Workman, J.E., \& Kidd, L.K. (2000). Use of the Need for Uniqueness Scale to Characterize Fashion Consumer Groups, Clothing and Textiles Research Journal, 18, 227-236.

[19] Roehrich, G. (2002). Consumer innovativeness, concepts and measurements, Journal of Business Research, 57(6), 671-677.

[20] Jordaan, Y., \& Simpson, M.N. (2006). Consumer innovativeness among females in specific fashion stores in the Menlyn shopping centre, Journal of Family Ecology and Consumer Sciences, 34, 32-40. 
[21] Evans, M. (1989). Consumer Behavior Toward Fashion, European Journal of Marketing, 23 (7), 7-16.

[22] Cholachatpinyo, A., Padgett, I. and Croker, M. (2002), "A conceptual model of the fashion process -part 1: the fashion transformation process model", Journal of Fashion Marketing and Management, 6 (1), 11-23.

[23] Piamhongsant, T., \& Mandhachitara, R. (2008). Psychological antecedents of career women's fashion clothing conformity, Journal of Fashion Marketing and Management, 12 (4), 438-455.

[24] Jannsen, M.A., \& Jager, W. (2001). Fashion, habits and changing preferences: Simulation of psychological factors affecting market Dynamics, Journal of Economic Psychology, 22,745-772.

[25] Lynn, M., \& Harris, J. (1997a). Individual differences in the pursuit of self-uniqueness through consumption, Journal of Applied Social Psychology, 27, 1861-1883.

[26] Lee, A. (2000). Adapting Triandis's Model of Subjective Culture and Social Behavior Relations to Consumer Behavior, Journal of Consumer Psychology, 9 (2), 117126.

[27] Dodd, C.A., Clarke, I., Baron, S., \& Houston, V. (2000), Looking the part': identity, meaning and culture in clothing purchasing - theoretical considerations, Journal of Fashion Marketing and Management, 4 (1), 41-8.

[28] Eastman, J.K., Goldsmith, R.E., \& Flynn, L.R. (1999), Status consumption in consumer behavior: scale development and validation, Journal of Marketing Theory and Practice, 7 (3), 41-51.

[29] O'Cass, A. (2004), Fashion clothing consumption: antecedents and consequences of fashion clothing involvement, European Journal of Marketing, 38 (7), 869882.

[30] Solomon, M.R., \& Rabolt, N.J. (2004). Consumer behavior in fashion, Prentice-Hall, Englewood Cliffs, NJ.

[31] Tian, K.T., Bearden, W.O., \& Hunter, G.L. (2001). Consumers' Need for Uniqueness: Scale Development and Validation, Journal of Consumer Research, 28, 5066.

[32] Snyder, C. R., \& Fromkin, H. L. (1980). Uniqueness: The human pursuit of difference. New York: Plenum Press.

[33] Goldsmith, R.E., \& Clark, R. (2008). An analysis of factors affecting fashion opinion leadership and fashion opinion seeking, Journal of Fashion Marketing and Management, 12 (3), 308-322.

[34] Bertrandias, L., \& Goldsmith, R.E. (2006). Some psychological motivations for fashion opinion leadership and fashion opinion seeking, Journal of Fashion Marketing and Management, 10 (1), 25-40.

[35] Okonkwo, U. (2007). Luxury Fashion Branding: Trends, Tactics, Techniques, Palgrave Macmillan, NY.
[36] Choi, T.-M. (Ed.), (2014), Fashion Branding and Consumer Behaviors: Scientific Models, Springer, NY, Heidelberg Dordrecht, London.

[37] Clayton, M. F., \& Pett, M. A. (2011). Modeling relationships in clinical research using path analysis Part II: Evaluating the model. Journal for Specialists in Pediatric Nursing, 16, 75-79.

[38] Kline, R. B. (2005). Principles and Practice of Structural Equation Modelling, Guilford Press.

[39] Raykov, T., \& Marcoulides, G. A. (2008). An Introduction to Applied Multivariate Analysis. New

[York: Taylor \& Francis.

[40] Hair, J.F., Black, W.C., Babin, B.J., Anderson, R.E., \& Tatham, R.L. (2006). Multivariate Data Analysis (6th ed.). Englewood Cliffs, N.J.: Prentice Hill.

[41] Chau, P.Y.K. (1996). An Empirical Assessment of a Modified Technology Acceptance Model, Journal of Management Information Systems, 13 (2), 185-204.

[42] Browne, M.W., \& Cudeck, R. (1992). Alternative Ways of Assessing Model Fit, Sociological Methods Research, 21(2), 230-258.

[43] Nunnally, J.C. (1978). Psychometric Theory, McGraw-Hill, New York.

[44] Keiser, H.F. (1974). An Index of factorial simplicity, Psychometrika, 39, 31-36.

[45] Kinnear, P.R., \& Gray, C.D. (1994). SPSS for Windows Made Simple, Psychology Press, Hove, UK.

[46] Bagozzi, R. P., \& Yi, Y. (1988). On the evaluation of structural equation models. Journal of the Academy of Marketing Science, 16, 74-94.

[47] Bagozzi, R.P., Yi, Y., \& Phillips, L.W. (1991). Assessing construct validity in organizational research, Administrative Science Quarterly, 36, 421-458.

[48] Hair, J.F., Black, W.C., Babin, B.J., \& Anderson, R.E. (2009).Multivariate Data Analysis, 7th edn, Prentice Hall, Upper Saddle River, NJ.

[49] Teo, T., Lee, C. B., Chai, C. S., \& Wong, S. L. (2009). Assessing the intention to use technology among preservice teachers in Singapore and Malaysia: A multigroup invariance analysis of the technology acceptance model, Computers \& Education, 53, 1000-1009.

[50] Crewe, L., and E. Davenport. (1991). The puppetshow: Changing buyer-supplier relationships within clothing retailing. Transactions of the Institute for British Geogaphers 17(2), 183-97.

[51] Bagwell, L.S., \& Bernheim, B.D. (1996). Veblen effects in a theory of conspicuous consumption, The American Economic Review, 86 (30), 346-373. 